\title{
Micro-grooving of brittle materials using textured diamond grinding wheels shaped by an integrated nanosecond laser system
}

\author{
Zongchao Geng ${ }^{1}$, Zhen Tong ${ }^{1 *}$, Wenbin Zhong $^{1}$, Guoqin Huang ${ }^{2}$, Changcai Cui ${ }^{2}$, \\ Xipeng $\mathrm{Xu}^{2}$ and Xiangqian Jiang ${ }^{1}$
}

1 EPSRC Future Metrology Hub, Centre for Precision Technologies, University of Huddersfield, Huddersfield, HD1 3DH UK

2 Institute of Manufacturing Engineering, Huaqiao University, Xiamen, Fujian, 361021, People's Republic of China

*Corresponding author: z.tong@hud.ac.uk

\begin{abstract}
The freeform surfaces including both the aspherical and prismatic concave/convex have been widely utilized in optical, electronical, and biomedical areas. Most recently, it is reported that grinding with structured wheels provides new possibility to generate patterns on hard and brittle materials. This paper reports the latest research progress on micro-grooving glass ceramic using laser structured bronze bond diamond grinding wheels. A nanosecond pulse laser is firstly integrated into an ultra-precision machine tool and used for the in-line conditioning of super abrasive grinding wheels, i.e. truing, dressing, and profiling/texturing. Meanwhile, an offset compensation method, considering the shifting depth of focus (DoF) at different laser irradiation position, is proposed to accurately generate various profiles on the periphery of the grinding wheels. Three types of patterns (riblets, grooves, and pillars) are successfully fabricated on the ceramic substrate using the laser textured grinding wheels. The results indicate that the integrated laser system offers high flexibility and accuracy in shaping super abrasive grinding wheels, and the grinding using textured grinding wheels provide a promising solution to generate functional structures on hard and brittle materials.
\end{abstract}

Keywords Laser processing; Super abrasive grinding wheels; Functional surfaces; Micro machining

\section{Introduction}

The surface texture has important influence on the performance of the components $[1,2]$. Recently, the application of single and multiscale structured surfaces increases significantly in optical, electronical and biomedical fields [3, 4]. For example, compressor blades of a gas turbine with riblets in 20-120 $\mu$ m width and 0.5 aspect ratio can reduce friction and avoid turbulences [5], and the micro holes and pillars can change the wet properties of surfaces [6]. Although many mechanical, physical and chemical methods have been developed to fabricate microstructures $[7,8]$, the grinding remains to be the most cost-effective method to fabricate structured surfaces on hard and brittle materials [9].

Grinding with micro abrasive tools (also called micro abrasive pencils or micro pencil grinding tools in some papers) and macro engineered tools are two most popular methods to generate micro/nano scale structures on 
hard and brittle materials [10]. Through depositing or coating grits layer on the base substrate such as cemented carbide, grinding with micro abrasive tools can produce smaller feather size on samples, but the problems of non-uniform protrusion height, clogging, and breakage hinder its application from machining with large allowance. In contrast, the engineered grinding wheel is prepared by generating specific micro profiles on periphery of macro grinding wheels, thus the tool strength has less weakened and enhanced tool life is achieved. To prepare the macro grinding wheels with structured profile, different patterns should be generated on the periphery of grinding wheels in advance, which is a challenging task for grinding wheels with super abrasive grains (i.e. diamonds and CBN). Traditionally, the mechanical conditioning method with such as diamond nibs, rollers, or dressing wheels is widely employed [11-13], but the conditioning tools are prone to serious wear after a period of working because the mechanical conditioning process is a hard to hard contact with large force engaged between grinding wheels and conditioning tools.

Recently, it is reported that the laser beam is capable of processing the grinding wheel with higher efficiency, greater flexibility and less pollution $[14,15]$. To the best of authors' knowledge, the earliest report on laser condition grinding wheels dates back to 1989 , when Ramesh [16, 17] used the Nd: YAG laser to dress aluminium oxide and silicon carbide grinding wheels. In his research, reduced grinding forces and improved surface finish were found during dry grinding carbon steel with the laser dressed tools. Since then, there are continuous efforts to investigate the effects of laser beam output (continuous or pulsed), wavelength, power, and polarization on the quality of laser conditioned grinding wheels [18]. For example, Wu et al. [19] fabricated a series of grooves $(\sim 300 \mu \mathrm{m}$ in width and $\sim 70 \mu \mathrm{m}$ in depth) on a coarse grain $(213 \mu \mathrm{m})$ diamond grinding wheel using a nanosecond pulse laser. Then linear and square microstructures were replicated on tungsten carbide and BK7 glasses by ultraprecision grinding. Deng et al. [20] investigated the influence of the spot overlap, line overlap, power, and scan cycles on bond smoothness of the grinding wheel. Their results indicated that the laser scan cycle should be carefully controlled to obtain good grain protrusion height. Furthermore, Ackerl et al. [21, 22] developed a multi-axis synchronized motion platform to improve the profile accuracy shaped by laser. Various cross-sectional shapes of grooves have been reported in [23, 24].

Nevertheless, the laser processing of grinding wheels is a complex interaction between the laser beam and grinding wheels, and it is affected by the absorption mechanism of laser beam, material properties of the irradiated sample, and surface morphology $[25,26]$. It is generally acknowledged that the irradiated material will be ablated if the threshold fluence $F$ (absorbed energy on unit area) is reached, but the threshold varies significantly even for the same material because of the incubation effect [27-29]. In practice, the guideline for selecting laser machining parameters relies greatly on users' experience, for example, using large fluence to remove both the bonding material and grains in truing, whereas using small fluence to selectively ablate the bonding materials to preserve the abrasive grains in dressing and cleaning. The literature on laser engagement in the whole conditioning process, i.e. truing, dressing, and texturing, is rare.

Tangential irradiation and radial irradiation are two typical configurations in laser conditioning of grinding wheels. The radial irradiation is used to quickly remove extra materials by rough truing or fine dressing the 
wheel to protrude the grains. On the other hand, the tangential irradiation aims to prepare the grinding wheel with more accurate profile. Research from Wang et al. [23, 30] showed that the absorbed energy for grinding wheels changed significantly at different radial position and incident angle because the space distribution of absorbed and scattered energy was far more different during laser irradiation. Therefore, the laser head should move along with the grinding wheel axis in order to keep the focus offset constant.

In this paper, a novel conditioning strategy using nanosecond pulse laser is developed for metal bond diamond grinding wheels. The whole conditioning process, including the truing, dressing, and texturing/profiling of the grinding wheel, is achieved using the same laser source. A preliminary test is organised to quickly choose proper processing parameters for different laser processing. An offset compensation value is calculated and used in laser profiling. The grinding capability of laser conditioned tools is demonstrated by generating riblets, grooves, and pillars on ceramic samples.

\section{Methodology}

\subsection{Experimental platform}

Fig. 1 (a) shows the laser conditioning configuration. A nanosecond pulse laser marking head (YLP-V2-1100-30-30, IPG) was integrated on $Z$ slide of an ultraprecision machine tool (Nanoform 250 Ultragrinder, Precitech). Two galvo motors were integrated into the marking head for adjusting the laser machining area. The minimum spot size was about $\varnothing 50 \mu \mathrm{m}$ in the focus plane. More details about the laser source are listed in Table 1. The \#1200 diamond grinding pin (Ø8x10 mm) was fixed on a tool holder which was then vacuum chucked on the spindle. The grinding wheel can move with the machine $X$ slide for the adjustment of the laser focusing distance. A confocal probe (CHRocodile S, Precitec), which had $100 \mu \mathrm{m}$ working range and 2 $\mathrm{kHz}$ sampling rate, was placed aside for measuring the radial runout before and after laser truing [31]. A USB microscopy (AM4815ZTL, Dino-Lite) was used to observe the process of laser conditioning and microstructure grinding.

The grinding configuration was shown in Fig. 1(b). A 25x25x5 mm glass ceramic substrate (Corning Macor) was vacuum chucked on the spindle by a special designed holder. The laser conditioned grinding wheel was clamped on an electro-spindle assembly (EM-3060J Motor, NR-3060S Spindle, and ARG-021E Gearbox, Nakanishi). The rough and fine alignment was achieved by the USB microscopy and feeler gauges, respectively. The Clairsol $330^{\mathrm{TM}}$ coolant mist was used throughout the grinding process. The laser conditioned wheels and ground samples were ultrasonic cleaned and then measured using non-contact optical 3D microscopy (Alicona G4 InfiniteFocus). More parameters about the grinding wheel and the sample were listed on Table 2. 

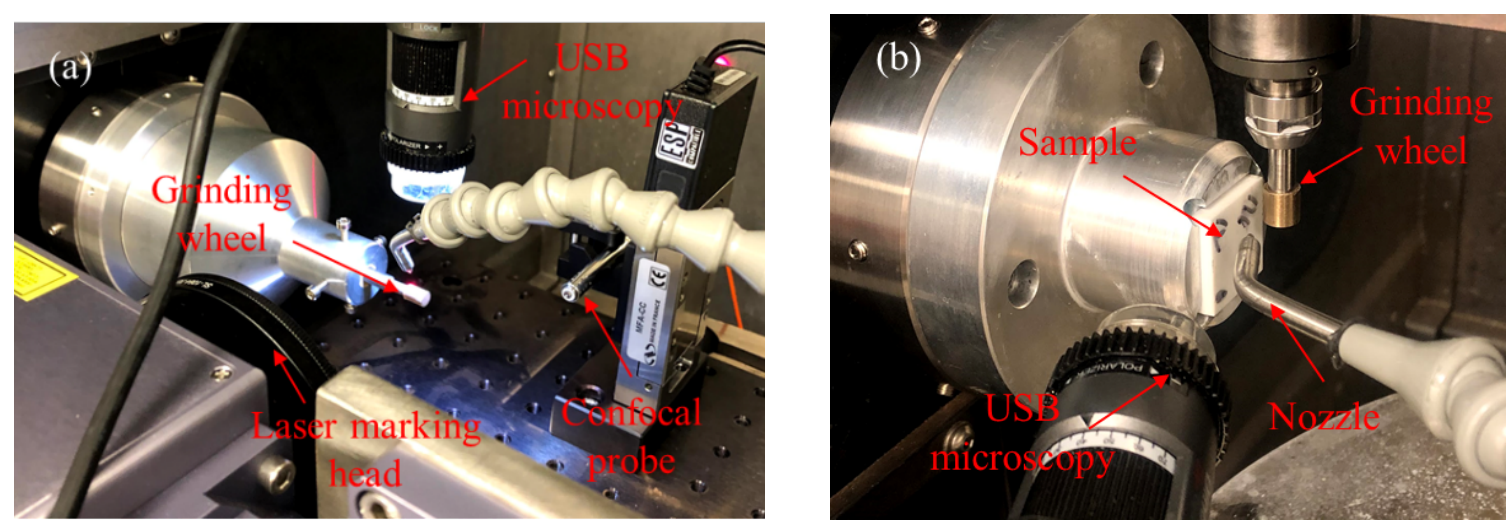

Fig. 1 Configuration for (a) the laser conditioning grinding wheel and (b) grinding microstructures on sample

Table 1 Parameters of the laser source

\begin{tabular}{llll}
\hline Parameters & Value & Parameters & Value \\
\hline Power, $p$ & $3-30 \mathrm{~W}$ & Wavelength, $\lambda$ & $1064 \mathrm{~nm}$ \\
Frequency, $f_{p}$ & $2-200 \mathrm{kHz}$ & Beam quality $M^{2}$ & 2 \\
Pulse duration, $\Delta \tau$ & $100 \mathrm{~ns}$ & Spot size & $\sim 50 \mu \mathrm{m}$ \\
Machining area & $60 \times 60 \mathrm{~mm}^{2}$ & Focal length & $100 \mathrm{~mm}$ \\
\hline
\end{tabular}

Table 2 Parameters of the grinding wheel and workpiece

\begin{tabular}{llll}
\hline Grinding wheel & \multicolumn{3}{c}{ Workpiece } \\
\hline Grain size & $\# 1200$ & Young's Modulous & $66.9 \mathrm{GPa}$ \\
Tool size & $\varnothing 8 \times 10 \mathrm{~mm}$ & Poisson's Ratio & 0.29 \\
Bonding & Bronze & Knoop Hardness & $250 \mathrm{~kg} / \mathrm{mm}^{2}$ \\
Concentration & $125 \%$ & Density & $2.52 \mathrm{~g} / \mathrm{cm}^{3}$ \\
\hline
\end{tabular}

\subsection{Experimental procedure}

In this experiment, a preliminary was planned to explore the laser machining ability and find the laser processing parameters for truing, dressing, and profiling the grinding wheel. The influence of laser machining parameters (pulse power $e$, pulse overlap $U_{p}$, line overlap $U_{l}$, and loops) on material removal rate and degree of graphitization was investigated. It is obviously that large pulse power, high pulse and line overlap, and more processing loops will increase the material removal volume and graphitization degree of diamond grits. Therefore, an orthogonal test $\mathrm{L}_{9}\left(3^{4}\right)$ with four three-level factors was arranged in Table 3 considering the laser specification. The pulse overlap and line overlap were calculated by Eq. 1 and Eq. 2 . The material removal volume of each $2 \times 2 \mathrm{~mm}$ square was measured by Alicona, and the degree of graphitization was evaluated by observing the optical image of laser irradiated surfaces, where serious 
graphitization was related to darker surface because diamond grits will transfer to black graphite at high temperature.

$$
\begin{aligned}
& U_{p}=1-\frac{\pi * D * S}{d * f} \\
& U_{l}=1-\frac{\text { pitch } * f}{d * S}
\end{aligned}
$$

Where the $D, S, d, f$, pitch represent the wheel diameter, wheel rotation speed, spot diameter, pulse frequency, and spot interval, respectively.

\begin{tabular}{|c|c|c|c|c|c|c|}
\hline Run & $\begin{array}{l}\text { Pulse energy } \\
\mathrm{mJ}\end{array}$ & Pulse overlap & Line overlap & Loops & $\begin{array}{l}\text { Graphitization } \\
\text { degree }\end{array}$ & $\begin{array}{l}\text { Removal volume } \\
\mathrm{mm}^{3}\end{array}$ \\
\hline
\end{tabular}

Table 3 Preliminary on laser ablation test

\begin{tabular}{ccccccc}
\hline 1 & 0.2 & $20 \%$ & $20 \%$ & 5 & + & 0.048 \\
2 & 0.2 & $50 \%$ & $50 \%$ & 10 & +++ & 0.176 \\
3 & 0.2 & $35 \%$ & $35 \%$ & 15 & ++ & 0.148 \\
4 & 0.6 & $20 \%$ & $50 \%$ & 15 & +++ & 0.648 \\
5 & 0.6 & $50 \%$ & $35 \%$ & 5 & ++++ & 0.456 \\
6 & 0.6 & $35 \%$ & $20 \%$ & 10 & ++ & 0.48 \\
7 & 0.4 & $20 \%$ & $35 \%$ & 10 & ++ & 0.12 \\
8 & 0.4 & $50 \%$ & $20 \%$ & 15 & ++ & 0.216 \\
9 & 0.4 & $35 \%$ & $50 \%$ & 5 & +++ & 0.344 \\
\hline
\end{tabular}

Fig. 2 presented the captured images of laser ablated nine pockets according to machining parameters in Table 3. It can be observed that the laser irradiated surfaces in the $2^{\text {nd }}, 4^{\text {th }}, 5^{\text {th }}$, and $9^{\text {th }}$ run were darker in colour, indicating severe graphitization of the diamond abrasive grits. The high line overlap (35\% to 50\%) was the common factor among the four groups. On the contrary, the laser machined surfaces in the $1^{\text {st }}$ and $3^{\text {rd }}$ run were bright, indicating less graphitization transition using small pulse energy $(0.2 \mathrm{~mJ})$ and low pulse overlap (20\%). Besides, it can be noticed from table 3 that more materials were removed in the $4^{\text {th }}, 5^{\text {th }}$, and $6^{\text {th }}$ run with $0.64848 \mathrm{~mm}^{3}, 0.45648 \mathrm{~mm}^{3}$, and $0.48 \mathrm{~mm}^{3}$, respectively, which showed that the pulse energy $(0.6 \mathrm{~mJ})$ had significant influence on the material removal. In summary, to balance the material removal volume and degree of graphitization, the maximum pulse energy (i.e. $e^{=1} \mathrm{~mJ}$ ) was chosen in laser truing for 
fast material removal, while small pulse energy (i.e. $e^{=0.2} \mathrm{~mJ}$ ) was used in dressing to remove the graphitization layer and protrude the diamond grains.
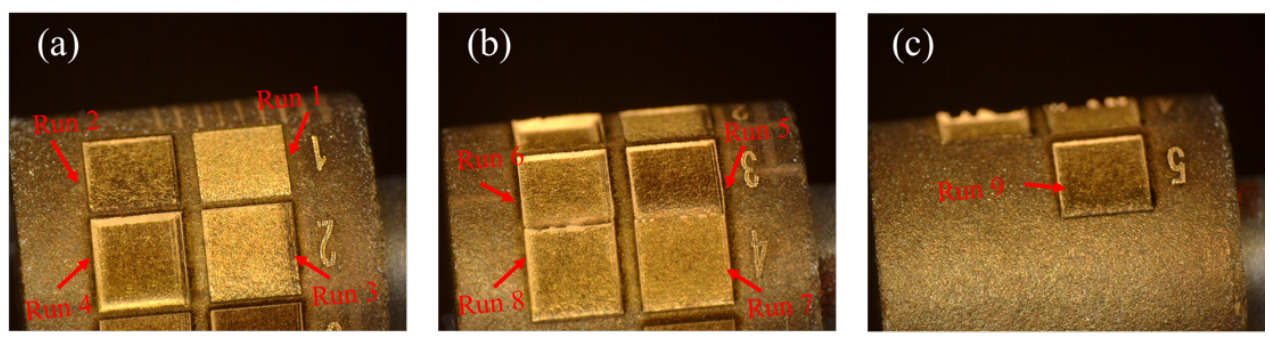

Fig. 2 The laser ablated pockets

The whole processing chain using laser beam to condition the grinding wheel was schematically shown in Fig. 3. Firstly, the radial runout of the grinding wheel was controlled within $\pm 1.25 \mu \mathrm{m}$ by the integrated gage. Then laser truing with $e=1 \mathrm{~mJ}, f=30 \mathrm{kHz}, S=1000 \mathrm{RPM}$, and $t=5$ min was performed to reduce the wheel radial offset and create the straight base line by repetitively scanning along the axial direction, as shown in Fig. 3 (a). The total removal depth was $100 \mu \mathrm{m}$ with two $50 \mu \mathrm{m}$ radial infeeds. After tangential truing, the laser dressing with low fluence ( $e=0.2 \mathrm{~mJ}, f=30 \mathrm{kHz}, S=1000 \mathrm{RPM}$, and $t=3 \mathrm{~min}$ ) was carried out to remove only the metal bonding and protrude diamond grains in Fig. 3 (b). The desired pattern was then produced through the layer-by-layer irradiating mode as shown in Fig. 3 (c). In order to improve the profile accuracy, a radial compensation strategy was adopted and schematically described in Fig. 3 (d). Along the laser beam propagation direction, most energy was focused within a narrow depth of focus $(D o F)$. The energy transferred to the grinding wheel will induce heat affected zone (HAZ) where the metal bonding material or diamond grains will be ablated if their fluence threshold is reached. However, when the truing line fed along radial direction, the laser should retreat a distance $A B$ to place the $D o F$ on the new exposed area of the grinding wheel. In this case, the $D o F$ was evaluated to be $\sim 850 \mu \mathrm{m}$ by Eq. 3. The radial compensation distance $A B$ was calculated according to Eq. 4. The radii of the grinding wheel was $4 \mathrm{~mm}$ and the profiling infeed $a$ was $30 \mu \mathrm{m}$, so the grinding wheel should move away $370 \mu \mathrm{m}, 520 \mu \mathrm{m}, 640, \mu \mathrm{m} 730 \mu \mathrm{m}$, and 820 $\mu \mathrm{m}$ respectively along the $\mathrm{X}$ slide at each laser profiling location.
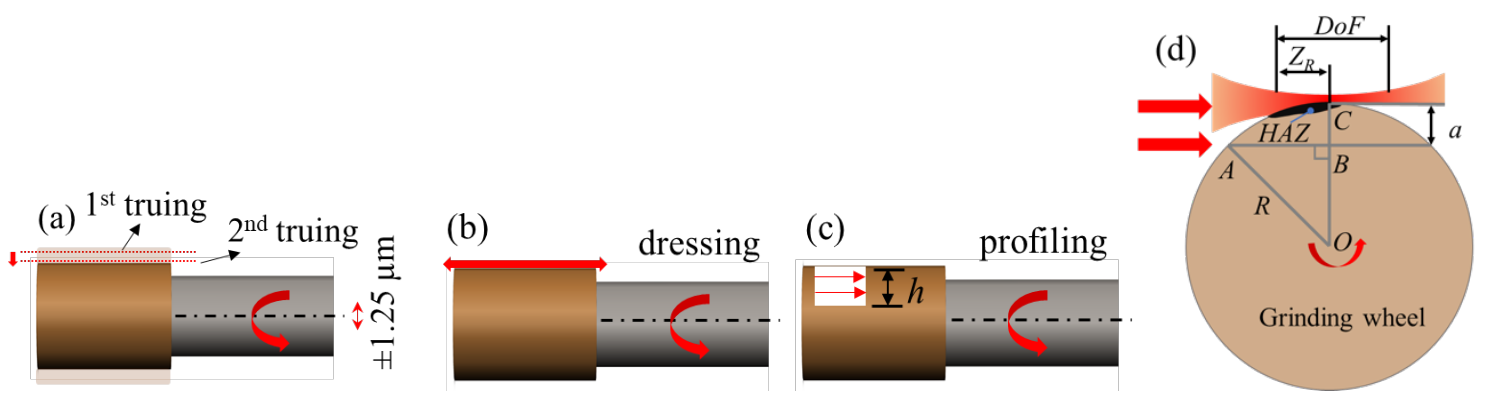

Fig. 3 (a) Laser truing (b) dressing (c) profiling, and (d) offset compensation

$$
D o F=2 * Z_{R}=\frac{2 \pi r^{2}}{\lambda M^{2}}
$$




$$
A B=\sqrt{R^{2}-(R-a)^{2}}
$$

Where $R, \lambda$, and $M^{2}$ are the wheel radius, laser wavelength, and beam quality, respectively.

\section{Results and discussion}

\subsection{Truing, dressing, and profiling}

Fig. 4 (a)-(c) showed the surface characteristics of the metal bond diamond grinding wheel at different laser conditioning phase, and the radial runout measured by the confocal probe was plotted in Fig. 4 (d)-(f). It can be noticed from Fig. 4 (a) that the as-received grinding wheel had rough surface and some contaminants were left. Large coaxiality and radial runout were observed in Fig. 4 (d) because of the mounting error and surface unevenness of the grinding wheel. After 5 mins truing, the laser ablation trajectory, indicated by the converted graphite in Fig. 4 (b), was clearly discovered on the wheel surface. Redundant bonding and abrasive materials were ablated by the high fluence laser. Then a precise concentricity was achieved, and the measured radial runout reduced to $\sim 20 \mu \mathrm{m}$ as shown in Fig. 4 (e). Followed by another 10 mins truing, the outer layer material of the grinding wheel was fully ablated. Then the laser beam would skim over the grinding wheel, and only a small part of the laser was projected to the wheel surface as shown in Fig. 3 (d). The absorbed and accumulated energy was insufficient, and the material removal volume reduced gradually. A quite smooth grinding wheel surface was generated as shown in Fig. 4 (c) and the radial runout furtherly decreased to $\sim 10 \mu \mathrm{m}$ in Fig. 4 (f).
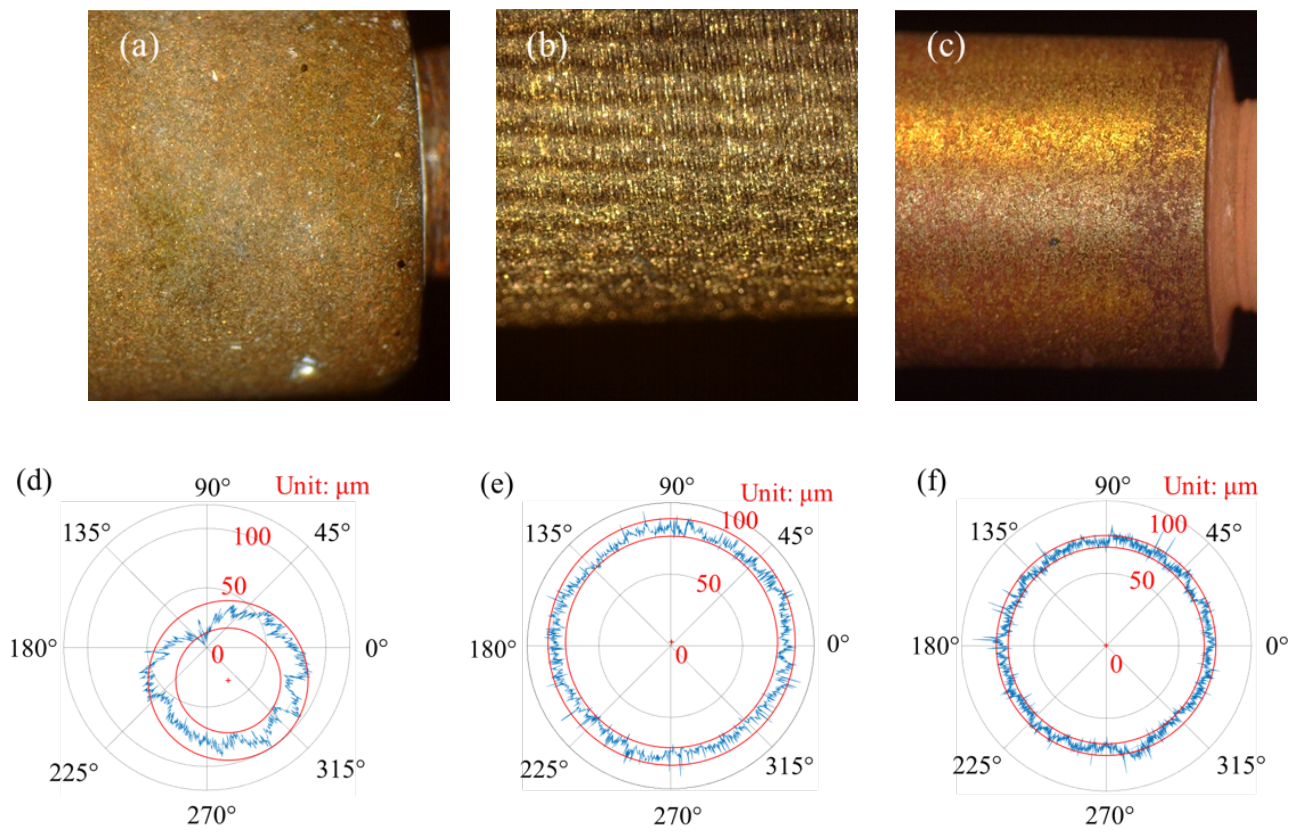

Fig. 4 The surface topography (a) before truing, (b) 5 min truing, (c) 10 min truing, and the radial runout (d) before truing, (e) 5 min truing, and (f) 10 min truing

Fig. 5 showed the surface micro topography and the statistical texture parameters of grinding wheels at different laser conditioning stages. To characterise the areal surface texture of the grinding wheel, the root mean square height $S_{q}$ and arithmetical mean height $S_{a}$ were selected to qualify the surface smoothness, 
while the reduced peak height $S_{p k}$ was used to describe the grain protrusion [32, 33]. As shown in Fig. 5 (a), the as-received grinding wheel had irregular surface $\left(S_{a} 16.3 \mu \mathrm{m}\right.$ and $\left.S_{q} 22.8 \mu \mathrm{m}\right)$ and abrasive grains were fully coved by bronze bonding. After 10 mins laser truing, most diamond grains were pulled off which led to massive pits and converted graphite in situ as shown in Fig. 5 (b). The grinding wheel was smooth with $S_{a}$ and $S_{q}$ less than $2 \mu \mathrm{m}$. After 5 mins laser tangential dressing with low fluence, the bronze bonding materials were melted and then blowed away by the compressed air. A large number of diamond grains were disclosed again as shown in Fig. 5 (c). The surface of grinding wheels became rough $\left(S_{a} 9.9 \mu \mathrm{m}\right.$ and $\left.S_{q} 14.2 \mu \mathrm{m}\right)$ and the grain protrusion height was approximately $5.3 \mu \mathrm{m}$ as characterised by $S_{p k}$. The dressing effect was satisfied because the protrusion height was within 1/3 1/2 of the grit size for \#1200 grinding wheel [18].
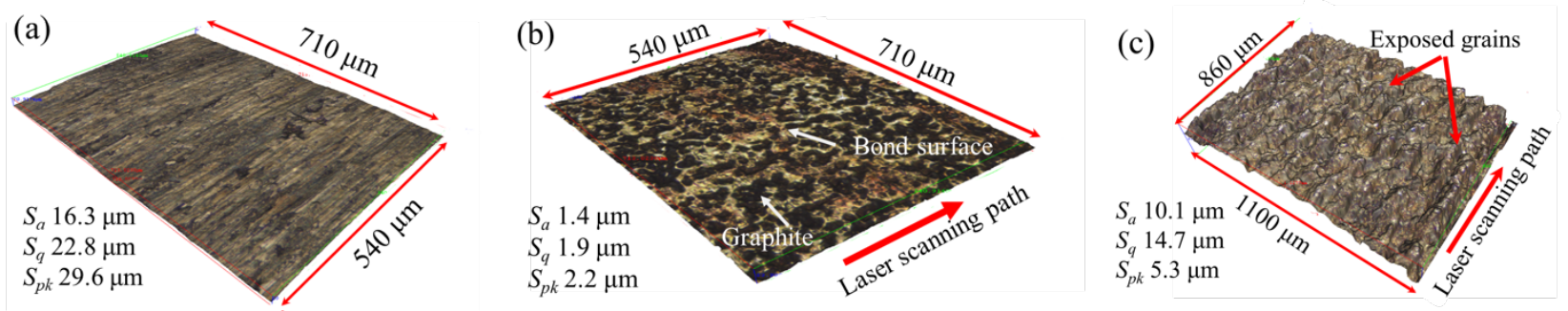

Fig. 5 The surface topography of grinding wheels (a) as received (b) truing and (c) dressing

Fig. 6 shows the textures and cross-sectional profiles of diamond grinding wheels shaped by both laser and mechanical dressing tip. The results indicate that the laser profiled grinding wheels has better uniformity in depth, and the profile dimension and chip space can be flexibly controlled (Fig. 6 (a) and (b)). To generate riblet structures with different dimensions, the grinding wheel was designed with $W 230 \mu \mathrm{m}, D 160 \mu \mathrm{m}$ and $W 150 \mu \mathrm{m}, D 300 \mu \mathrm{m}$ as shown in Fig. 6 (a). For the rectangle grooves and pillar array, the grinding wheel was prepared with $W 250 \sim 500 \mu \mathrm{m}$ and $D 110 \mu \mathrm{m}$ as shown in Fig. 6 (b). Although some resolidified layer was found on the entrance of the grooves, these materials can be easily removed in grinding. In contrast, the mechanically profiled grinding wheel using diamond nib had large form deviation due to the diamond tip wear and elastic back-off of the grinding wheel (Fig. 6(c) and Fig. 6(d)).
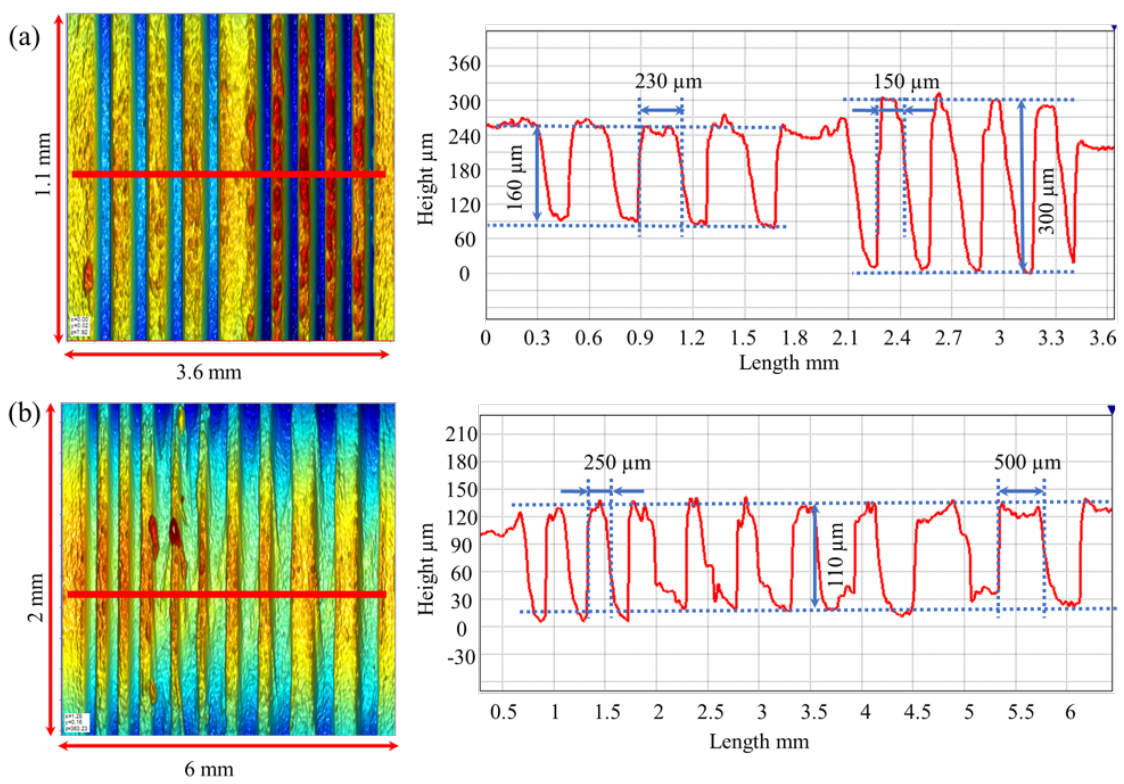

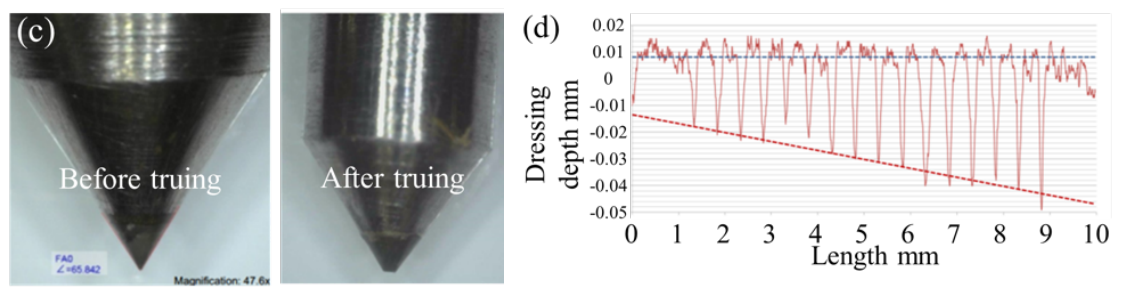

Fig. 6 (a) (b) The laser profiled metal bond grinding wheels, (c) the diamond dressing nib, and (d) conditioned grooves on resin bond grinding wheel (image (c) and (d) are reproduced from [12])

\subsection{Grinding with textured wheels}

To demonstrate the grinding capability of laser conditioned diamond grinding wheels, three types of popularly used microstructures (the riblets, grooves, and pillar array) were machiend in Fig. 7 to Fig. 9, respectively. The riblets and rectangle grooves were processed with plunge grinding mode, while the pillar array was fabricated by twice plunge grinding with the workpiece $90^{\circ}$ apart. The depth of grinding was 120 $\mu \mathrm{m}$ for pillars, and $80 \mu \mathrm{m}$ for rectangle grooves and pillar array, respectively. Other parameters were set at $S=40000 \mathrm{RPM}, D o C=10 \mu \mathrm{m} /$ pass, $f=5 \mathrm{~mm} / \mathrm{min}$, and $v=16.7 \mathrm{~m} / \mathrm{s}$, respectively.

Fig. 7 showed the overview and close-up of the ground riblets on ceramic glass. Two groups of riblets with different period $(P=300 \sim 450 \mu \mathrm{m})$ and depth $(H=120 \sim 140 \mu \mathrm{m})$ were successfully machined on the ceramic glass. The width of riblets increased from $20 \mu \mathrm{m}$ on top to $200 \mu \mathrm{m}$ on bottom. The structure has uniform profile accuracy along the $14 \mathrm{~mm}$ length. The surface roughness $S_{a}$ was measured to be $2.1 \mu \mathrm{m}$ on the ground surface. Compared to the method proposed in [34], where 6 thin dicing blades are assembled and carefully aligned on a shank to fabricate riblet structures on an impeller, the strategy developed in this paper requires only one laser conditioned grinding pin. Besides, the internal grinding wheel can be easily re-conditioned after wear, which significantly reduces the cost and increases productivity in the long term. Therefore, the developed grinding strategy provides a promising alternative to generate riblets on turbo machinery components.
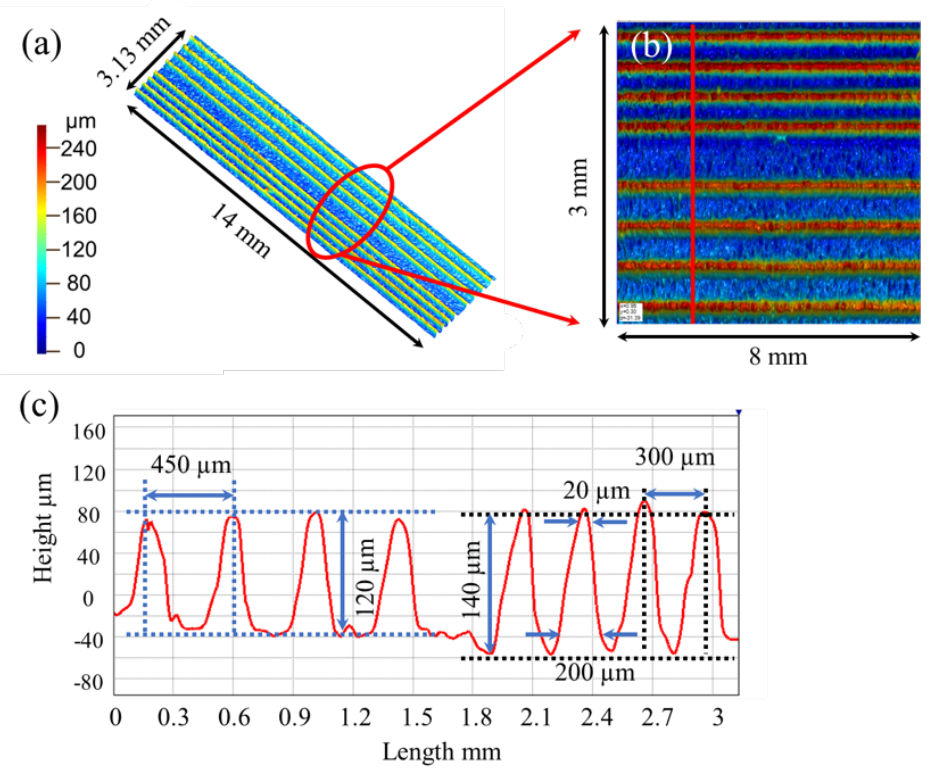

Fig. 7 (a) Overview, (b) local and (c) 2D profile of the riblet structures 
Similarly, Fig. 8 showed the overview and close-up of the ground rectangular grooves (14 $\mathrm{mm} \mathrm{X} 4 \mathrm{~mm})$ on the ceramic glass. The ground rectangle grooves were $80 \mu \mathrm{m}$ in depth and $150-310 \mu \mathrm{m}$ in width within the ground range. The aspect ratio was 1.8 3.8 and the surface roughness of the ground surface was $S a 1.6 \mu \mathrm{m}$. Compared to the riblet structures in Fig. 7, the rectangular groove had even width from top to bottom, which is required in microfluid devices [35].
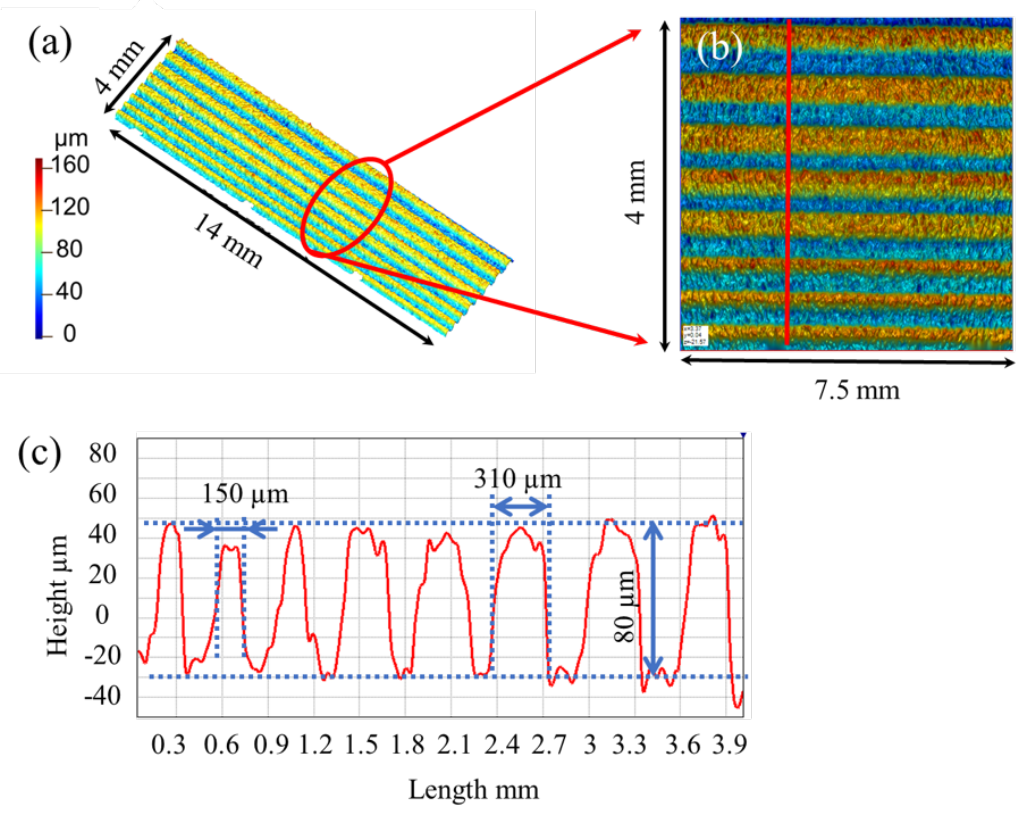

Fig. 8 (a) Overview, (b) local and (c) 2D profile of the rectangle structures

Fig. 9 (a) outlined the ground pillar array in a $5 \times 6 \mathrm{~mm}$ square area. The intersection of twice plunge grinding generated a variety of pillars with different dimension. Three groups of pillars, as selected by red, black, and yellow squares, were extracted to show more details in Fig. 9 (b), (c), and (d), respectively. Squares with $\sim 300 \mu \mathrm{m}$ length and 50-80 $\mu \mathrm{m}$ depth were produced with period at about (b) $770 \mu \mathrm{m}$, (c) $610 \mu \mathrm{m}$, and (d) $490 \mu \mathrm{m}$. The depth of ground pillar array decreased gradually from the left bottom corner $(\sim 80 \mu \mathrm{m})$ to the top right corner $(\sim 50 \mu \mathrm{m})$ because of mounting unevenness of the sample. The height consistency can be improved by introducing a flat grinding before grinding microstructures.

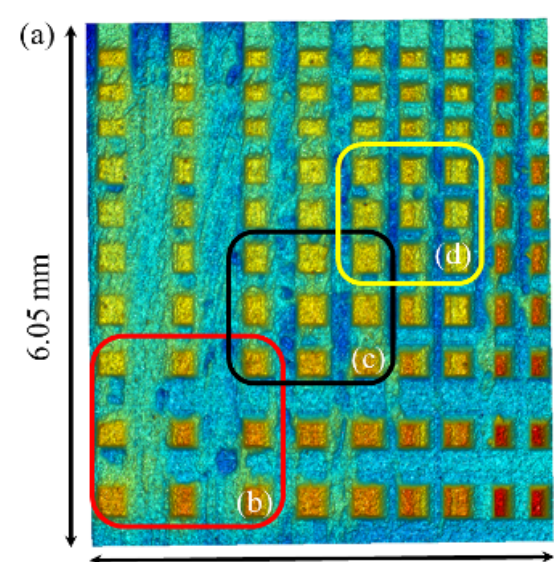

$5.12 \mathrm{~mm}$
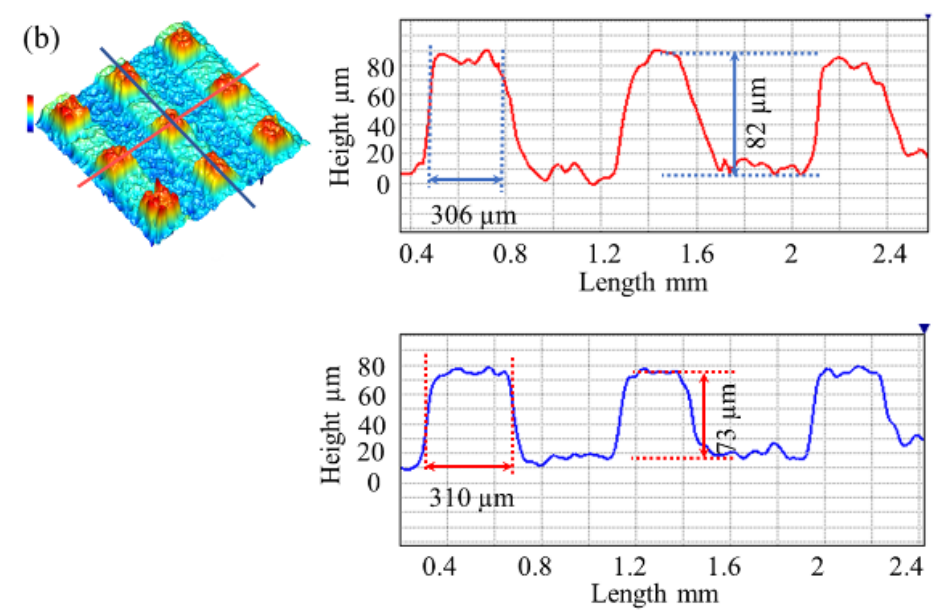
(c)
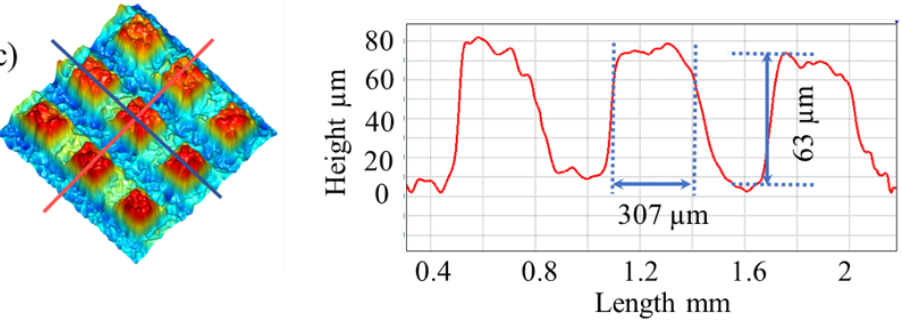

(d)
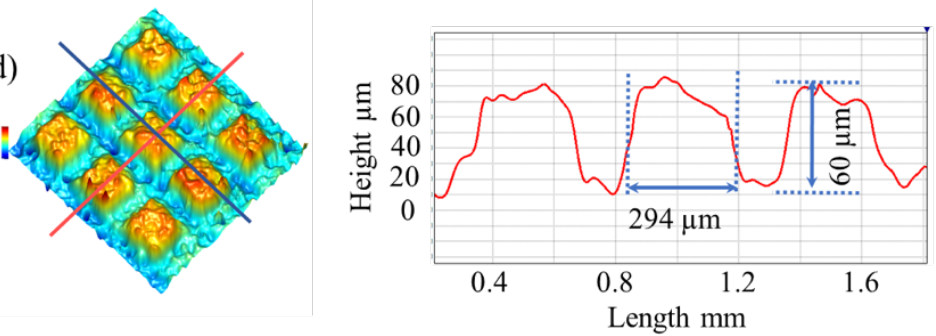
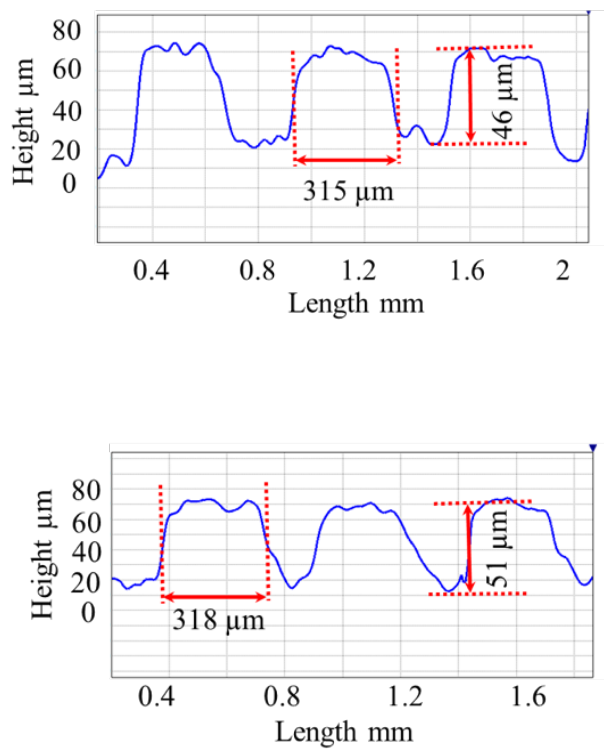

Fig. 9 (a) Overview and (b)-(d) close-up of the pillar array

The surface topography of the diamond grinding wheel after grinding pillar arrays was shown in Fig. 10. It can be noticed that the average profile height reduced to around $70 \mu \mathrm{m}$ after grinding pillars. Compared to the fresh conditioned grinding wheel with profile height of $110 \mu \mathrm{m}$ in Fig. 6 (b), the wear was about $40 \mu \mathrm{m}$ in height. For the macro wear of the grinding wheel, the grinding ratio, defined as the material removal volume divided by the volume of wheel wear, was estimated to be 6.3-6.5 in machining riblets and rectangle grooves. For the micro wear of the grinding wheel, the areal roughness was measured at $S_{a} 1.5 \mu \mathrm{m}$ and $S_{q} 1.9$ $\mu \mathrm{m}$, while the abrasive protrusion decreased from $S_{p k} 5.3 \mu \mathrm{m}$ to $S_{p k} 1.4 \mu \mathrm{m}$.
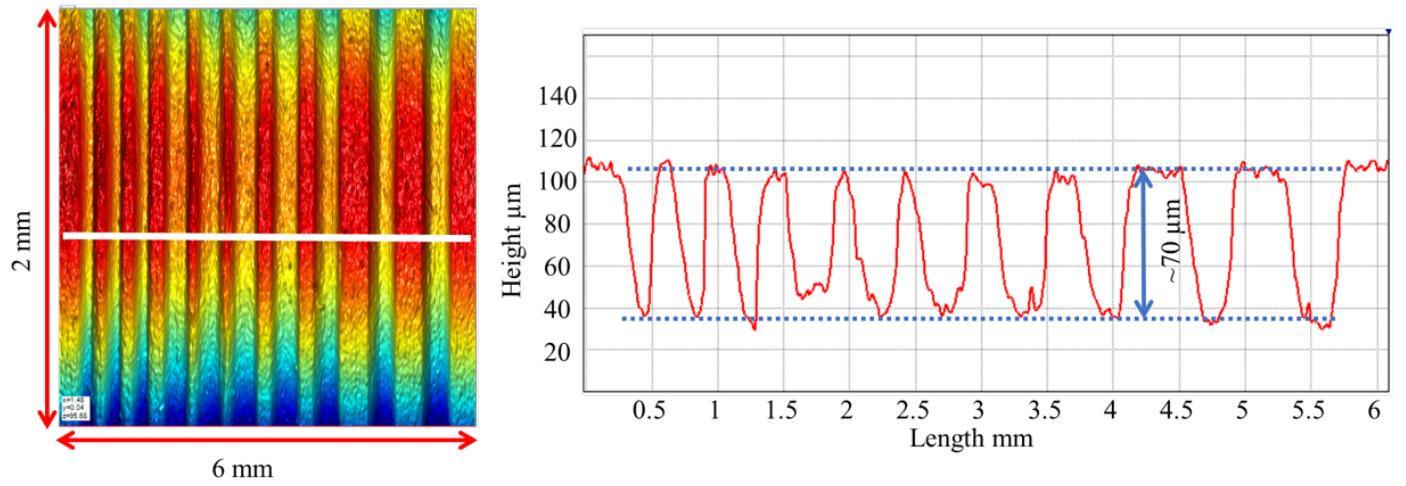

Fig. 10 The geometry topography of the grinding wheel after machining pillar array

\section{Conclusion and future work}

This paper proposed a functional surface grinding method using the laser conditioned diamond grinding wheels. The truing, dressing, and profiling of the metal bond diamond grinding wheel were achieved using the nanosecond pulse laser beam. Three popular types of functional structures were machined using the laser processed diamond grinding wheels. Main conclusions and future development are summarised as follows: 
- The nanosecond pulse laser is excellently involved in the whole conditioning process of super abrasive grinding wheels, i.e. truing, dressing, and profiling/texturing. The radial runout is well controlled within $10 \mu \mathrm{m}$ after laser truing and the trued surface is very smooth $(S a 1.4 \mu \mathrm{m})$. After laser tangential dressing with low energy fluence, the fresh abrasive grains are successfully protruded with $5.3 \mu \mathrm{m}$. Profiles with different sizes and shapes are flexibly generated on wheel periphery for microstructure grinding.

- The laser conditioned grinding wheels show significant potential to generate microstructures on workpiece. Riblets, rectangle grooves and pillar array have been successfully fabricated with different width, height, and period. The grinding wheel has $40 \mu \mathrm{m}$ wear in height after grinding and the grinding ratio is about 6.3-6.5.

- The laser conditioning accuracy can be further improved by optimizing the laser machining parameters, using ultrashort pulse laser beam and synchronising the motion platform and laser source. Other types of patterns can be explored on the grinding wheels according to different requirements.

Acknowledgments The authors would like to acknowledge the funding support from the UK's EPSRC Future Metrology Hub (Ref: EP/P006930/1), the European Union's Horizon 2020 research and innovation programme under grant agreement No. 767589, flexible open research funding of Institute of Manufacturing Engineering of Huaqiao University, and the China Scholarship Council (CSC).

\section{Declarations}

Ethics approval and consent to participate: Research participants were not subjected to harm in any ways whatsoever. The respect for the dignity of all the research participants had been prioritized, and full consent was obtained from the participants prior to the research study.

Consent for publication: The authors consent to Springer the non- exclusive publication rights and warrant that their contribution is original and that they have full power to make this grant.

Competing interests: The authors declare no competing interests.

\section{References}

[1] Malshe AP, Bapat S, Rajurkar KP, Haitjema H (2018) Bio-inspired textures for functional applications. CIRP Ann 67:627-650. https://doi.org/10.1016/j.cirp.2018.05.001

[2] Bruzzone AAG, Costa HL, Lonardo PM, Lucca DA (2008) Advances in engineered surfaces for functional performance. CIRP Ann - Manuf Technol 57:750-769. https://doi.org/10.1016/j.cirp.2008.09.003

[3] Brinksmeier E, Karpuschewski B, Yan J, Schönemann L (2020) Manufacturing of multiscale structured surfaces. CIRP Ann 69:717-739. https://doi.org/10.1016/j.cirp.2020.06.001

[4] Tong Z, Zhong W, To S, Zeng W (2020) Fast-tool-servo micro-grooving freeform surfaces with embedded metrology. CIRP Ann 69:505-508. https://doi.org/10.1016/j.cirp.2020.04.111

[5] Hockauf R, Asadi E, Denkena B, et al (2018) Grinding of riblets with "beaver tooth" multi-layer tools. Procedia CIRP 71:155-159. https://doi.org/10.1016/j.procir.2018.05.089

[6] Shin S, Seo J, Han H, et al (2016) Bio-inspired extreme wetting surfaces for biomedical applications. Materials (Basel) 9:. https://doi.org/10.3390/ma9020116

[7] Zhang S, Zhou Y, Zhang H, et al (2019) Advances in ultra-precision machining of micro-structured 
functional surfaces and their typical applications. Int $J$ Mach Tools Manuf 142:16-41. https://doi.org/10.1016/j.ijmachtools.2019.04.009

[8] Tong Z, Zeng W, Zhong W, Jiang X (2021) A closed-loop feature-based FTS patterning and characterisation of functional structured surfaces. Surf Topogr Metrol Prop 9:25012. https://doi.org/10.1088/2051-672X/abedf8

[9] Uhlmann E, Mullany B, Biermann D, et al (2016) Process chains for high-precision components with micro-scale features. CIRP Ann 65:549-572. https://doi.org/10.1016/j.cirp.2016.05.001

[10] Aurich JC, Kirsch B, Setti D, et al (2019) Abrasive processes for micro parts and structures. CIRP Ann 68:653-676. https://doi.org/10.1016/j.cirp.2019.05.006

[11] Oliveira JFG, Bottene AC, França T V (2010) A novel dressing technique for texturing of ground surfaces. CIRP Ann 59:361-364. https://doi.org/https://doi.org/10.1016/j.cirp.2010.03.119

[12] Young C (2018) Ultra-precision Abrasive Machining of Functional Structured Surfaces. Doctoral thesis. University of Huddersfield. http://eprints.hud.ac.uk/id/eprint/35061

[13] Guo B, Zhao Q (2015) Mechanical truing of V-shape diamond wheels for micro-structured surface grinding. Int J Adv Manuf Technol 78:1067-1073. https://doi.org/10.1007/s00170-014-6721-7

[14] Li HN, Axinte D (2016) Textured grinding wheels: A review. Int J Mach Tools Manuf 109:8-35. https://doi.org/10.1016/j.ijmachtools.2016.07.001

[15] Deng H, Xu Z (2019) Dressing methods of superabrasive grinding wheels: A review. J Manuf Process 45:46-69. https://doi.org/10.1016/j.jmapro.2019.06.020

[16] Babu NR, Radhakrishnan V, Murti YVGS (1989) Investigations on laser dressing of grinding wheelspart I: Preliminary study. J Manuf Sci Eng Trans ASME 111:244-252. https://doi.org/10.1115/1.3188756

[17] Babu NR, Radhakrishnan V (1989) Investigations on laser dressing of grinding wheels-Part II: Grinding performance of a laser dressed aluminum oxide wheel. J Manuf Sci Eng Trans ASME 111:253-261. https://doi.org/10.1115/1.3188757

[18] Azarhoushang B, Zahedi A (2017) Laser conditioning and structuring of grinding tools - a review. Adv Manuf 5:35-49. https://doi.org/10.1007/s40436-016-0167-0

[19] Wu M, Guo B, Zhao Q, He P (2018) Precision grinding of a microstructured surface on hard and brittle materials by a microstructured coarse-grained diamond grinding wheel. Ceram Int 44:8026-8034. https://doi.org/10.1016/j.ceramint.2018.01.243

[20] Deng H, Deng Z, Li S (2016) Study on methods to optimize laser-sharpening quality, efficiency and topography. Precis Eng 46:409-416. https://doi.org/10.1016/j.precisioneng.2016.05.005

[21] Ackerl N, Warhanek M, Gysel J, Wegener K (2020) Ultra-short pulsed laser conditioning of metallicbonded diamond grinding tools. Mater Des 189:108530. https://doi.org/10.1016/j.matdes.2020.108530

[22] Ackerl N, Gysel J, Warhanek M, Wegener K (2019) Ultrashort pulsed high power laser conditioning of super-abrasive grinding worms. In: Kaierle S, Heinemann SW (eds) High-Power Laser Materials Processing: Applications, Diagnostics, and Systems VIII. SPIE, p 3

[23] Wang XY, Wu YB, Wang J, et al (2005) Absorbed energy in laser truing of a small vitrified CBN grinding wheel. J Mater Process Technol 164-165:1128-1133. https://doi.org/10.1016/j.jmatprotec.2005.02.108

[24] Walter C, Rabiey M, Warhanek M, et al (2012) Dressing and truing of hybrid bonded CBN grinding tools using a short-pulsed fibre laser. CIRP Ann - Manuf Technol 61:279-282. https://doi.org/10.1016/j.cirp.2012.03.001

[25] Boerner P, Hajri M, Ackerl N, Wegener K (2019) Experimental and theoretical investigation of ultrashort pulsed laser ablation of diamond. J Laser Appl 31:022202. https://doi.org/10.2351/1.5096088 
[26] Mishra S, Yadava V (2015) Laser Beam MicroMachining (LBMM) - A review. Opt Lasers Eng 73:89122. https://doi.org/10.1016/j.optlaseng.2015.03.017

[27] Butler-Smith PW, Axinte DA, Daine M (2009) Preferentially oriented diamond micro-arrays: A laser patterning technique and preliminary evaluation of their cutting forces and wear characteristics. Int $\mathrm{J}$ Mach Tools Manuf 49:1175-1184. https://doi.org/10.1016/j.ijmachtools.2009.08.007

[28] Wu M, Guo B, Zhao Q, et al (2018) The influence of the focus position on laser machining and laser micro-structuring monocrystalline diamond surface. Opt Lasers Eng 105:60-67. https://doi.org/10.1016/j.optlaseng.2018.01.002

[29] Hosokawa A, Ueda T, Yunoki T (2006) Laser dressing of metal bonded diamond wheel. CIRP Ann Manuf Technol 55:329-332. https://doi.org/10.1016/S0007-8506(07)60428-4

[30] Wang XY, Wu YB, Kang RK, et al (2005) Energy-mode adjustment in laser processing a small vitrified CBN grinding wheel. Key Eng Mater 291-292:177-182. https://doi.org/10.4028/www.scientific.net/KEM.291-292.177

[31] Tong Z, Zhong W, To S, Zeng W (2020) Fast-tool-servo micro-grooving freeform surfaces with embedded metrology. CIRP Ann 69:505-508. https://doi.org/10.1016/j.cirp.2020.04.111

[32] ISO 25178-2 Geometrical product specifications (GPS) - Surface texture: Areal

[33] Wegener K, Hoffmeister HW, Karpuschewski B, et al (2011) Conditioning and monitoring of grinding wheels. CIRP Ann - Manuf Technol 60:757-777. https://doi.org/10.1016/j.cirp.2011.05.003

[34] Denkena B, Grove T, Harmes J (2016) Grinding of riblets on curved paths. Mater Sci Forum 874:28-33. https://doi.org/10.4028/www.scientific.net/MSF.874.28

[35] Lee S-JJ, Sundararajan N (2010) Microfabrication for microfluidics. Artech house 